\title{
Taxonomy-The Crucial yet Misunderstood and Disregarded Tool for Studying Biodiversity
}

\section{Qudsia Tahseen*}

Nematode Research Laboratory, Department of Zoology, Aligarh Muslim University, Aligarh-202002, India

*Corresponding author: Qudsia Tahseen, Nematode Research Laboratory, Department of Zoology, Aligarh Muslim University, Aligarh-202002, India, Tel: 919319624196; E-mail: qtahseen@yahoo.com

Rec date: Mar 15, 2014, Acc date: Apr 26, 2014, Pub date: May 07, 2014

Copyright: ( 2014 Tahseen Q, This is an open-access article distributed under the terms of the Creative Commons Attribution License, which permits unrestricted use, distribution, and reproduction in any medium, provided the original author and source are credited.

\begin{abstract}
This article presents a detailed overview about one of the most important yet neglected fields of science, the Taxonomy, its relevance and the various impediments faced by it in recent times. Since the period 2011-2020 has been declared the Biodiversity decade, the Convention of Biodiversity has laid major emphasis on the inventory and conservation of biodiversity. However, it is a fact that the ignorance about our faunal and floral wealth can be detrimental for our own survival. With the decline in taxonomy and the disappearance of taxonomists worldwide, we are slowly heading towards a state of uncertainty and chaos as most of our studies require an accurate identification of test organism which is not a job that anyone or everyone can do. Therefore, this article highlights the stringent measures that are required to be taken by the taxonomists as well the various policy making agencies towards the revival and promotion of Taxonomy.
\end{abstract}

Keywords: Biodiversity; Taxonomy; Impediments; Initiatives; Impact factor

\section{Introduction}

"How many species are there on our planet?" is a simple and obvious question that comes to the mind of every person but is very difficult to answer. Our ignorance regarding the real magnitude of the world's biodiversity is enormous (May 2011). Taxonomists have so far described less than 2 million species [1,2], although an accurate estimate of the species existing on our planet is difficult to make due to the possibility of duplications (synonymies) or gaps in the record. Even we know very little about most of the 'described' species [3,4]. The estimated total numbers of species unknown to science range from $7-8$ to 50 or 100 million or even more [5-8]. Invertebrates comprise about $97 \%$ of the total animal species and thus present the largest gap in our knowledge and many species playing critical role in nitrogen fixation, decomposition and soil conditioning are unknown. It will require 5000 taxonomists to complete merely the taxonomic listing of 5 million species in 25-30 years if one taxonomist can deal with 1000 species [9]. However, the 'biodiversity crisis' [10] created by human civilization has resulted in drastic reduction and extinction of biodiversity due to disappearance of habitats, pollution and overexploitation. Over the past half a billion years, the world lost perhaps one species per million each year whereas the current annual rate of extinction is estimated to be 1000 to 10000 times faster [11]. By 2050, the biodiversity loss is expected to be equivalent to $7 \%$ of the World's GDP. About 70 species have been reported to be extinct during the last 600 years, however, the others vanished before discovery or description, remain unknown and unrecorded [12-15]. Taxonomy hence is needed the most today with the escalating threat to biodiversity $[16,17]$. In order to conserve biodiversity, five strategic goals and 20 ambitious yet achievable targets (Aichi Targets) have been set for the biodiversity decade (2011-2020) by the signatory countries of the Convention on Biological Diversity.

\section{Taxonomy, The science}

The word taxonomy as derived from the Greek words, taxis (= arrangement) and nomos (= law), deals with the description and classification of organisms, essential to the inventory of life on earth $[18,19]$. Taxonomic history $[20,21]$ can be traced from the time of Aristotle, the Greek philosopher who proposed the first basic classification; whereas its modern form dates back nearly 250 years, when Carl Linnaeus (1707-1778), the founding father of modern taxonomy, introduced the binominal scheme and the principles of biological classification. He (l.c.) put together in 1753, the first systematic catalogue of life on earth (Species plantarum) with classification and description of around 7,000 species. In order to avoid redundant descriptions or duplication of names, specific rules have been proposed as International Code of Zoological Nomenclature (ICZN 1999) for recognizing, naming and classifying species and are continuously monitored by international commission scientists [22]. Taxonomy has undergone remarkable changes since the time of publication of Systema Naturae [23] and the implementation of zoological nomenclature (1999).

The discipline of taxonomy traditionally covers three levels of studies viz., alpha (analytical phase), beta (synthetic phase) and gamma (biological phase) taxonomy [24,25]. Alpha taxonomy is the level at which the species are recognized and described; beta taxonomy refers to the arrangements of the species into a natural system of lower and higher categories on the basis of relationships, and gamma taxonomy is the analysis of intra specific variations, ecotypes, polymorphisms, phylogeny etc.

Taxonomy involves field-oriented study; and to undertake the task one should have a non-biased mind and the passion to explore the undiscovered fauna and flora. It requires careful observation, analytical thinking and an intelligent evaluation to identify and describe taxa. Traditionally, it may take several days or even months to arrive at a conclusion to identify a taxon and may also involve elaborate consultations with group experts. 


\section{The subdivisions}

The different branches of 'New Systematics' [26] have further provided new tools for taxonomic identification. The homology or the relationship of taxa can be determined by the qualitative and quantitative analyses of the chemical compounds viz., amino acids, carbohydrates and lipids (chemotaxonomy); the antigen and antibody reactions particularly the homologous or heterologous ones (serotaxonomy); the karyotype study and the chromosome structure (cytotaxonomy); behavioural attributes viz., feeding, nesting, breeding, altruistic, social, territorial behavior etc. (ethotaxonomy) and ecological characteristics including habitat preference and functional status in the environment (ecotaxonomy). Another field of study, the 'Numerical Taxonomy' takes into account greater number of characters from many sets of data (morphological, behavioral, karyological, etc) with each character having equal weight, in order to produce a similarity-based phenetic classification. The study involving morphological or phenotypic interpretation, also called as 'Classical or 'Conventional Taxonomy', is the basic taxonomy that has been practiced since past. Molecular taxonomy, a sister or co- discipline of chemotaxonomy, is relatively a recent branch of taxonomy, raised by workers of molecular biology. It includes genotype study including DNA barcoding, analyses of isozymes, molecular cytogenetics and a number of other related parameters. DNA barcoding uses a short genetic marker in the mitochondrial DNA (mtDNA) as an identification label of a species. One of the main differences between molecular and classical taxonomy is that the former usually relies on fine and sophisticated techniques using micro amount of DNA/RNA from the organism while the latter characterizes organism as a whole [27] emphasizing on its general appearance or phenotype.

\section{Relevance}

Taxonomy is usually the basis for a number of meaningful studies and is considered an important basic science giving skeletal support to many other sciences. The scientific name of an organism is a functional label using which any information concerning the organism can be obtained [28]. The findings of genome projects, medical science discoveries or conservation programmes will be inconclusive or irrelevant if the test species remains unidentified or incorrectly identified. The success of pest management programmes lies in correct identification of both pest and the natural enemy species [29]. Therefore, the absence of taxonomic consultation in such projects often results in tremendous loss of agricultural products as well as money [16,29-31]. Taxonomists in biosecurity and quarantine services check the entry of exotic species of parasites or pathogens through imported material. Taxonomy is also essential in many other fields viz., commerce, environmental problems, predictive modeling, evolutionary biology, fisheries, medicine, mineral prospecting through the dating of rocks by their enclosed fauna and flora, public health, wild life management, soil fertility etc. [24]. Even the biological weapons used in wars require taxonomic expertise for the identification of organisms.

Overall, taxonomy helps to understand and sustain the various types of dynamic ecosystems that exist on our planet with species showing great flexibility and adaptability. It further enhances the authenticity of the ecological studies and increases the accuracy of simulation modeling. The study of all species further facilitates a better understanding of their origin and diversification and the evolutionary history by integrating morphological, molecular, developmental information. A large number of species are being used worldwide for human well-being and economic development [32] and many more are still to be explored or understood for betterment. A proper mapping of biodiversity with detailed biogeography will be valuable for easy access of the useful bio resources. With only around $10 \%$ of the world's biota described so far $[11,25]$, there is a growing need for credible taxonomic information in order to conserve, manage and promote the sustainable use of biological resources [5,6,33,34]. A unique name is assigned to a species owing to its distinctness in morphology, anatomy, genome, behaviour, placement in the food web, ecological interactions, the distribution patterns and phylogenetic position. However, for such taxonomic processes, the overall support to the taxonomy and taxonomists is not up to the mark [35].

\section{The roadblocks}

With tremendous unaccounted biodiversity on Earth, the societal need of taxonomy is greater than ever. However, there are taxonomic roadblocks as the resources supporting taxonomy are becoming scarcer $[10,35,36]$ thus impeding the process of conservation and management. Removal of some of the following impediments is very necessary for inventorying and conserving the world's biodiversity.

Shortage of man power: Taxonomists provide insights into biodiversity hence they can be regarded as key information providers in biology and life sciences. [11,37] estimated about 6000-10000 taxonomists worldwide with few working in developing countries that hold most of the Earth's biodiversity. This small taxonomic community has a skewed distribution of expertise and more than $80 \%$ of taxonomists are close to, or older than, 50 years of age [38]. There exist gaps in expertise, particularly among ecologically, phylogenetically or economically important taxa. Despite their increasing importance in today's biodiversity crisis, most taxonomists particularly those working on descriptive taxonomy, are facing with sense of insecurity and discouragement with their work considered to be old-fashioned and non-rewarding [39]. The work done by original author(s) of the species is rarely accredited [40-42] or included in the literature cited. The model Escherichia coli is being cited in over $1,640,000$ publications but its original author has been cited only 58 times. Likewise, Caenorhabditis elegans Maupas 1900 is one of the most cited species but the author has been cited in very few instances. It might be argued that such citations might take enough space in the publications in case of multiple species; however, they do not seem to be longer than GenBank sequences/ alignments that constitute an essential component of most modern publications.

Young scientists are rarely recruited into taxonomy and systematics $[38,43]$ and there is considerable decline in the number of positions in taxonomy in Europe and other parts of the world [25,44]. In many natural history museums, the position created after retirement of a taxonomist is not filled. Consequently, the basic sciences, Zoology and Botany are gradually disappearing from university curricula and new entrants in biodiversity usually end up studying molecular biology or ecology [45]. The decreasing number of taxonomists is correlated with lesser number of taxonomic centers and inadequate taxonomic training. The importance of taxonomy in relation to biodiversity management is an aspect largely missing from the curricula of most institutes.

Lack of funding: Taxonomy is suffering from a serious lack of funding. Taxonomists nested in university departments suffer from a sense of isolation as majority of faculty from different disciplines of science, have greater amounts of funding and working teams. Funding for taxonomy is inadequate ignoring thousands of unknown species 
that are likely to be threatened or endangered $[35,46]$. In fact, the theoretical and technological advances in phylogeny reconstruction and molecular biology both have attracted greater funding but have also given a setback to traditional taxonomy [47] and the basic understanding of morphology.

Unavailability of old literature: The relevance of old publications in taxonomy remains the same over time and, consequently, original descriptions have to be referred to forever, irrespective of the paper's quality or the publisher's name. Access to great libraries is difficult for students and scientists in developing countries. It is a fact that there are some online duly- compiled and updated taxonomic databases (e.g., ASEAN, BHL, EoL, Gallica, ITIS, Animal Base etc.). The Biodiversity Heritage Library is in the process of digitizing 250 years of legacy literature. Wilson's et al. [12] vision for a Web page for every species is being realized by the Encyclopedia of Life. Nevertheless, retrieval of old taxonomic literature is a difficult task. Making all descriptive taxonomic literature digital and openly available is a major task to promote quality in taxonomy. The unavailability of literature impacts the taxonomic process; and in absence of a proper comparison, the identification often leads to synonymy or erroneous phylogenetic assumptions. The literature retrieval and exchange in the taxonomic groups with few working specialists, is often not easy. Further, many old or retired taxonomists are not computer-savvy hence not able to send or retrieve literature, electronically. In many instances, the recent non open access, online publications hold subscription or copy right issues and cannot be accessed easily in developing countries.

Prejudiced and biased approach: Taxonomy is often regarded by some progressive workers as outdated science with taxonomists depicted as postage-stamp collectors [37]. Species description is seen as an obsolete way of doing research and the availability of species identifications for life science studies, is often taken for granted. Furthermore, there is a tendency among young and modern ecologists to view museums and herbaria as "dusty" places with old-fashioned people working on them [48]. As a result, usually people doing some applied work are preferred over taxonomists in various selection/ promotion processes. The involvement of taxonomists in other administrative research activities may be detrimental and will lead to dilution of the taxonomic outputs.

Lopsided and irresponsible ranking: Impact Factor (IF) was introduced as a tool for selecting the popular scientific journals for coverage in the Science Citation Index [49]. Many journals of Museums or of taxonomic literature with low citation rate did not receive an IF or very low one and hence were not included in SCI list. The IF of a journal, as now managed by Thomson Reuters, reflects the number of citations received in the Impact Factor year to content published in the preceding two years, divided by the number of articles and reviews published in those two years [50]. IF was also used as a metric for librarians to make decisions about the journals to be purchased or discontinued [51,52]. However, the way of ranking journals went over its original scope and was overwhelmingly used as an "evaluation metric" to assess the professional competence of scientists [53]. It is a fact that number of citations over a two-year period does not necessarily indicate 'quality'; even the citation profiles of journals are often skewed with a few highly cited articles raising the average value of IF. The published work may also be of different nature viz., on a new methodology, a review of a specific topic, positive or negative comments about a technique, discussion, important science results, new discovery, new species etc. Moreover, the journals receiving same IF number do not necessarily have the same worth and quality across subject categories. The IF is meaningful only in the context of journals with similar scientific content. Publishing in a high impact journal does not ensure that the paper will have many citations. Besides, IF can be manipulated by a journal's editor by promoting selfcitation thus encouraging authors to cite papers published in its journal [52]. Seglen et al. [54] stated that American scientists who regularly cite each other's work raise both the citation rate and the mean journal impact of American science 30\% above the world average. The sciences of systematics and taxonomy invite less citations $[32,42,55-57]$ hence in many countries, the use of IF or Citation Index to assess the merit of scientific papers for jobs and promotions can often lead to insidious consequences [58]. The Nobel Prize winner Sydney Brenner (1995) has aptly stated, "Before we develop a pseudoscience of citation analysis, what matters absolutely is the scientific content of a paper, and nothing will substitute for either knowing or reading it".

Another index, Cited Half Life (CHL) introduced by Institute for Scientific Information (ISI) could have been considered for evaluation of scientific excellence, which estimates how long the average article of a journal is likely to be cited,. It is a fact that most of the journals with high IF do have low CHL whereas the Law of priority prevents any taxonomic paper containing the description of a species from being forgotten; therefore, its CHL is infinite. Nevertheless, the modern scientists chose what suited them the most [53]. Hence IF was considered a fundamental or the only criterion for assessing scientific excellence and for assigning resources/ opportunities in academic market. Unfortunately, many of the taxonomic journals are not included in the ISI list (which means $\mathrm{IF}=0$ ), and even if they are included, their IFs are very low as compared to other scientific journals. IF, as calculated by the ISI, is inapplicable in taxonomy due to the following reasons $[55,59]$.

-The taxonomic descriptions especially the original descriptions are important and referred to forever, irrespective of the paper's quality;

-Many taxonomic groups/ taxa have just a few specialists to work on, therefore, their chance to be cited are rare, compared with popular/ general disciplines. As a result, many excellent super specialized publications may be cited too less frequently.

-Identification keys provided in taxonomical papers are important but usually not documented in the reference list or bibliography of papers.

Keeping in view the problem, a person with average quality paper published in high IF journal is preferred over a candidate with a high quality taxonomic paper published in a low impact factor journal or in Memoires of a Museum that is not covered by Science Citation Index (SCI). The IF system is also contributing to the extinction of $\alpha$ taxonomists as the latter are switching to new methods and fields to gain some IF respectability in order to boost their career.

Other weaknesses: Besides some external factors, there is also a need for the taxonomists to do some introspection or self-appraisal to improve the conditions. The following attitudes of taxonomists add to their woes.

-Lack of confidence: The taxonomists have not been able to convince others about the importance of their work; or in other words, have not been confident and tactful to 'sell their product' properly [1]. According to Boero et al. [45] the decline of taxonomy is due to taxonomists themselves as they always complain about the 
deteriorating situation while sitting on the microscopes, but do not seem to be trying to solve the problem. It is ironical that astrobiologists are receiving funds from funding agencies for studying life on other planets while taxonomists are not able to convince those agencies to fund them for studying the life of this planet only.

-Lack of will and commitment: Some of the taxonomists are not committed to work and lack enthusiasm. Numerous reasons exist for this unfortunate approach. In some cases, the taxonomists behave irresponsibly and dishonestly when they sign on to a project merely to get a sponsored trip to the remote unexplored locations for the sake of fun and adventure [36]. Some taxonomists stop working and publishing due to other obligations (administration, bioinformatics, teaching loads, travel, meetings, phylogenetic analyses etc.) and in other cases demand authorship in students' papers to keep their "name alive". However, there are some researchers who do not have any of these excuses, yet are labeled as taxonomists.

-Lack of vision: According to Godfray et al. [20], many taxonomists lack clear perception of the relevant goals e.g., describing every species of Earth is definitely not a realistic goal. They very often are ignorant about the question to be asked. Most taxonomists, following the old legacy of taxonomy, spend most of their time interpreting the work of nineteenth-century workers and comparing type materials from world's museums, often in very poor condition. This is one of the reasons that taxonomists fail to attract large-scale funds. The growing rift [60] between the classical and molecular taxonomists due to their rigid attitude, biased thinking and narrow vision is giving another serious blow to taxonomy which could survive better after integration.

-Lack of consistency: Taxonomists are often accused of creating confusion with change in species concept leading to elevation of subspecies to species [61] thus influencing greatly the studies on macro ecology and conservation.

The introduction of 'Phylocode' [Phylogenetic Nomenclature (PN) code] in 1998 as a substitute to the prevailing Linnaean binomial scheme-based codes of zoological, botanical and microorganism nomenclature [rank-based nomenclature (RBN) code], has been enthusiastically promoted by a group of scientists [7-9,62-64,68-71]. However, it also received severe criticism from many workers $[10,72-82]$ who did not find it a good decision. Under the Phylocode scheme, a scientific name (a uninomen) is to be defined in relation to its position on phylogenetic tree. Thus the rejection of the old code (RBN) or the use of both naming codes in taxonomy will create confusion and chaos for no gain [83]. The task of generating Phylocode definitions and solving problems will divert taxonomists from their core work and will further be detrimental for the growth of taxonomy.

-Lack of credibility: In some cases, the work for collecting and studying organisms is done by 'Para taxonomists', i.e. people with a little knowledge of biodiversity in native regions, working on lower salaries than professionals. Hence species are not identified, but the specimens are grouped in RTUs (Recognizable Taxonomic Units) or morpho species. Although Para taxonomy can be justified in some huge projects involving lots of survey work but its abuse could be dangerous for future [84] since RTUs are not described or named according to the rules of ICZN (2008, revised 2012). Even for molecular studies, the dependence on such personnel can lead to erroneous findings. As a result we may have the DNA sequences piled up in GenBank of the species which are incorrectly identified. Thus the mistakes in the sequence data need to be removed ideally to include them in nomenclatural data. Furthermore, majority of barcoding sequences are of little value as they are not identified to species [85]. When research in other fields never depends on low salaried 'Para scientists' and part timers, how can taxonomy be left on the mercy of such Para taxonomists?

Another problem of non-credibility encountered is of selfpublication as well as publication in non-peer reviewed and obscure journals which may be done primarily by those who only want to see their name in print and really do not care about experts' opinion or dissipation of bogus information to others.

-Non representation in key positions: It is a fact that IF of taxonomical journals is low compared to other scientific journals; and usually IF is used as a parameter to assess research excellence for various research positions/ funding etc. Therefore, the proposals submitted by a good number of taxonomists for funding are likely to be unsuccessful. Furthermore, because of the supposedly low impact work, most taxonomists are not elected/ nominated as members in selection boards or panels of granting bodies or policy making committees to make any difference.

\section{The solutions}

It is indeed the time to assess the task accomplished in conservation and management of the estimated $90 \%$ of the world's unknown biodiversity. Thus the major objective is the creation of a catalogue of life in order to provide available information about any organism and depicting its position on the tree of life. Keeping in view its gradually depleting status, certain concrete measures should be taken for the revival of taxonomy and its keepers, the taxonomists.

-Taxonomy should be projected not only as an attractive subject to the beginners but also as more challenging as well as productive than most sophisticated sciences because it introduces a new or unknown world for discovery and exploration [58]. The subject should be included in the curricula and syllabi from higher secondary school to postgraduate level and the students encouraged to take up taxonomy as their career. Specialized pre-doctoral and doctoral teaching in taxonomy should be available.

-The role of Natural history museums can be very crucial in educating the general public/ society, the importance of diversity, taxonomy and historical distributions of species through the material available over the internet [48]. Furthermore, there should be educational activities between scientists and children, the next generation taxonomists. Computerization of collections and preparation of e-catalogues may provide new techniques for curating collections [86]. The public should be made aware of the importance of organisms in ecosystem functioning and in other fields in order to change its perception. News regarding species discovery, wildlife documentaries, photography books or exhibitions and the arts in general is the effective ways of gaining public support.

-There should be enough openings or employment opportunities for taxonomists in museums, universities and other research institutions without any prejudice or bias. According to $[87,88]$, taxonomy needs working time in the field and laboratory; hence the taxonomists should be given full positions and should not be underpaid because finances often dictate how a job is completed.

- "The statistical parameters viz., impact factor and h-index are always not very meaningful (JCQAR 2008) still they are being predominantly used all over the world. It is inappropriate to use the 
same yardstick for the assessment of the taxonomic papers as well as papers of applied and molecular biology. Seglen et al. [54] has rightly concluded ". As long as there are people out there who judge science by its wrapping rather than by its contents, we cannot afford to take any chances." However, proper initiatives should be taken to provide scientific recognition to those working on an aspect not considered by the IFs. In the other case, assessment should not be based on the IF value of the journal but on the status/ rank of the journal in the concerned field and recognized by ISI.

-Proper funding should be provided to taxonomists or concerned organizations and institutes for field work and for the permanent storage of specimens and information attached to them, and for publishing taxonomic revisions and monographs. Attempts should be made to procure all possible information on the species related to their diverse ways of life, functional roles and consequently their sensitivity to habitat change, that usually remain unknown or scattered [89]. Taxonomists of several recognized institutions can work for the development of instantly accessible electronic archives of such taxonomic databases [90].

-The work of taxonomists particularly of original authors should be cited along with taxon's name and included in the literature cited thus validating the scientific status of the test organism and increasing the credibility of results. Further, the taxonomic material viz., monographs, keys, primary taxonomic literature and revisions when used for identification should be cited like any other methodological reference to enhance the reliability of taxonomic information.

-Taxonomists should be included as co-authors when they make substantial contributions or when the conclusions are solely dependent on the accurate identification of the test species. Authors working on projects involving large species data sets could do so to increase communication and collaboration as well as the accuracy of the vetted work [39]. Likewise, without a good, constantly updated taxonomy, biodiversity and conservation studies are meaningless [61,91-93].

- Taxonomy by following traditional ways of species description, will never deliver the greatest benefits. Thus radical changes are needed to accelerate the rate of discovery and description if diversity is to be documented in a realistic time frame while facing global change. Taxonomy should evolve with meaningful and innovative changes in the taxonomic process viz., use of new and improved tools and systems to accelerate characterization, comparison and differentiation of taxa. Gaston \& O’Neill et al. [94] pointed out that automated species identification should make a "valuable contribution to reducing the burden of routine identifications". The image of an organism for image library creation can be analyzed using automated or semiautomated methods of digital phenotype capture. Such image analysis facilitates turning of raw pixel data into morphological characters. However, it poses a lot of problems as the ways of image analysis by humans and machines differ significantly and some morphological features obvious to human eye are not detected by machine algorithms, and vice versa. The human visual system's ability can be exploited to detect changes in images while the capacity of computers can be utilized to rapidly collate and correlate [95] large numbers of images and to detect distinctive morphological features [96,97] related to colour [98], shape and size [99], texture [100]. Thus a data matrix can be populated using morphological characters to describe and hypothesize evolutionary relationships. Cyber taxonomy utilizes digital technology, information and computer technology to enhance the quality and quantity of taxonomic output [46]. However, the use of these new generation-tools requires properly trained taxonomists working in conjunction with computer scientists and software engineers to evaluate ancestral and derived characters while studying comparative morphology. Nevertheless, too much thrust on computerization of research, statistical data and on molecular approaches, will not solve the problem [101-103] as statistics can mislead when misapplied or misunderstood" [104]. Systems currently operational using automated identification, include: DAISY (Digital Automated identification System), ABIS (Automated Bee Identification System), SPIDA (Species Identification Automated). These are reviewed in [105].

-The integration of molecular data with morphological information is an important part of the taxonomic process. By making gene sequences from type materials readily available, researchers will be able to rapidly identify undescribed species, new populations, or synonyms. DNA barcoding facilitates short, standardized gene regions to automate species identifications and is very useful for identification of cryptic species $[22,106,107]$. Although few modern taxonomists feel that molecular taxonomy can prove extremely crucial using a variety of genes $[108,109]$ yet molecular methods on their own cannot replace morphological interpretations [110]. The main problem is the variability within and between species [16] as recently diverged species might not be distinguishable on the basis of DNA bar coding (CO1 sequences). In order to understand a species, it is absolutely essential to study it as a whole organism and not only by DNA sequences or bar codes $[102,111]$. DNA barcoding or DNA sequences can be used as supplementary tool for matching molecular data with morphological data to assess genotype-phenotype relationship. Although the hightech descriptions using molecular taxonomy are regarded more scientific by some workers [27], classical taxonomy is still very crucial and relevant [112].

-To elevate the status of taxonomy, the taxonomists are required to demonstrate enthusiasm, commitment and accountability towards this neglected science. They must identify the root cause of any taxonomic impediment and should have a vision to respond to it. Unfortunately, some taxonomists follow the same old practice without thinking to solve the problem rather they use the problem to support their thinking. While documenting life on Earth they must do an exhaustive literature search with honesty and passion to compare taxa with those already described, otherwise it would simply lead to large scale synonymy or duplicated work.

\section{Brighter side of the picture}

United States has taken the lead to do some corrective measures against the dismissal of classical taxonomy [113]. Considering the gradual decline of the subject, National Science Foundation launched in 1995 the Partnerships to Enhance Expertise in Taxonomy (PEET) and later, the Assembling the Tree of Life (AToL), Revisionary Syntheses in Systematics (RevSys) and Planetary Biodiversity Inventory (PBI) were started. PEET program has provision of funding research projects, enabling intensive training of young people from different countries and focusing on poorly known taxa for revisionary or monographic research. Many of the PEET trainees have been able to secure employment in the USA and other countries [1,114]. Some projects viz., EDIT (European Distributed Institute of Taxonomy, CATE (Creating a Taxonomic e-Science) and TRIN (Taxonomic Research and Information Network) aiming to increase taxonomic productivity with the use of e-Research, networking and collaboration, 
coordination of expertise, knowledge sharing, and the creation of virtual workspaces, have also been funded.

In 2004, as many as twenty European natural history museums and botanic gardens received the integrated infrastructure initiative grant to access the world's natural history collections, library support, facilities for microscopy and physical, chemical and molecular analyses besides networking. Other similar programmes conducted in different countries include SYS-RESOURCE (Great Britain), COLPARSYST (France), COBICE (Denmark), HIGH-LAT (Sweden), BIOIBERIA (Spain) and $\mathrm{ABC}$ (Belgium). A number of other initiatives are very crucial to overcome the taxonomic impediment and provide a foundation to accelerate the taxonomic process through collaboration, resource sharing and delivery of biodiversity data thus making the taxonomy fashionable.

Tremendous resources have been made available to user community through a number of global scale initiatives. Few of these portals are Encyclopedia of Life (EoL, Global Biodiversity Information Facility (GBIF), GenBank, Atlas of Living Australia (ALA), Species 2000, ITIS Catalogue of Life, MorphBank, ZooBank the official online registry for Zoological Nomenclature and Biodiversity Heritage Library (BHL). Despite these initiatives the real bottleneck is the production of information itself although advances in information handling and interpretation are producing remarkable shifts in publications. The electronic format of the journal's web-based papers with embedded links and a variety of cyber taxonomic tools enhance the quality and relevance of publications [115]. The initiatives of value-adding $[116,117]$ to taxonomic papers involves authenticating and streamlining the taxonomic process as pointed by Zhang et al. [118] in the following ways

- Registration of new species in the official ZooBank registry developed by the International Commission on Zoological Nomenclature.

- Marking of descriptive data with SDD (TDWG standard for Descriptive Data) to enable direct downloading of raw data or marking species descriptions with XML tags using standards in TaxonX.

- Creating hyperlinks to images deposited in the MorphBank or DNA Barcodes deposited in GenBank.

-Citing specimens with embedded links to online databases in museums and/or via the GBIF portal.

\section{What future holds?}

There is little doubt that web-based applications, products and publications indicate the future of taxonomy. Automating taxon identification will be an important component of any future system that will help overcome the taxonomic impediments. The developments in digital technology, information science and computer engineering will facilitate better management of information and improved networking and collaboration. With the steadily decreasing cost of imaging and data storage it will be easy to capture and record high quality and high resolution images of specimens from different angles. Use of RAPID (Robotic Automated Pest ID) will facilitate automated sorting of field generated samples, sample feeding, image analysis, and relational databases $[119,120]$.

For cyber taxonomic applications, artificial intelligence, a universal, systematic and structured language of descriptive morphology and other pattern recognition tools will help define character states, determine homologies etc. This will further aid in recognition and extraction of morphological characters from raw images in order to prepare "character matrix" for sorting specimens into known and novel species. The merits of electronic publication and open access for species descriptions are well evident. Taxonomic data will be accessible on-line and specimens' character matrices will be used to automatically produce diagnoses, keys, field guides, revisions, monographs, and phylogenetic trees. Thus taxonomists will be able to prepare any work dealing with large number of species in relatively short time and the web-based revisions can be regularly done with digitization of new specimens integrating information on biology, ecology, distribution, trophic associations etc. Such initiatives will accelerate the taxonomic research and delivery and ultimately a vast biodiversity knowledge bank can be available for policy management and research plannings.

\section{Conclusion}

Despite the technological advancements, we have not been able to automatically extract all the morphological data from images of specimens. It would still require many centuries to complete the inventory of over 10 million species [121] living on earth even if we double our existing pace of taxonomic work i.e., about half a million species / 100 years. Therefore, the best way to achieve the timely description is by providing a trained taxonomic work force with suitable funding and support, combined with new specialized technologies developed to accelerate the taxonomic process. Instead of trying to create the entire range of technological advances for automation, the taxonomic community should collaborate with experts in areas of image capture and analysis/ feature extraction, statistical analysis, syntax pattern recognition, software engineering and architecture, bioinformatics and 3D imaging to aptly use state of the art techniques. Other bottlenecks that limit the rate of taxonomic achievement [122] such as finding and collecting specimens in the field sorting, mounting and processing, will also need attention and automation if possible. The benefit of naming all species of the planet is that it would provide the necessary information about biodiversity decline besides contributing to the species information bank thus helping in resource management, biosecurity, predictive modeling, predictive classification etc.; although apparently it does not seem to advance the science of taxonomy. Nevertheless, we should not be desperate about expediting the descriptive process, but rather in making it more meticulous and evolutionarily relevant. Taxonomists, therefore, must provide robust hypotheses about natural entities and about the relationships of taxa and must embrace the integrative strength of comparative and molecular biology [103,123-125] in order to enhance the value of taxonomy and biological collections.

\section{References}

1. Guerra-García JM, Espinosa F, García-Gómez JC (2008) Trends in Taxonomy today: an overview about the main topics in Taxonomy. Zoologica baetica 19: 15-49.

2. La Salle J, Wheeler Q, Jackway P, Winterton S, Hobern D et al. (2009) Accelerating taxonomic discovery through automated character extraction. Zootaxa 2217: 43-55.

3. Dubois A (1998) List of European species of amphibians and reptiles: will we soon be reaching "stability"? Amphibia-Reptilia 19: 1-28.

4. Dubois A (2010a) Zoological nomenclature in the century of extinctions: priority vs. usage. Org Divers and Evol 10: 259-274.

5. Groombridge B (1992) Global Biodiversity: Status of the Earth's Living Resources. A Report compiles by the World Conservation Monitoring 
Centre London, Glasgow, New York, Tokyo, Melbourne, Madras: Chapman \& Hall.

6. Heywood VH (1995) Global biodiversity assessment. Cambridge University Press, Cambridge 1140.

7. Reaka-Kudla ML, Wilson DE, Wilson EO (1997) Biodiversity II. Washington, Joseph Henry Press: i-vii+1-551.

8. Cherian PT (2004) Getting the measure of India's insect diversity: 41-54. Perspectives on Biosystematics and Biodiversity (eds. Rajmohana K, Sudheer K, Girish P, Santosh S) TCN Com: 1-666.

9. González-Oreja JA (2008) The Encyclopedia of life vs. the brochure of life: exploring the relationships between the extinction of species and the inventory of life on Earth. Zootaxa 1965: 61-68.

10. Wilson EO (1985) The biodiversity crisis: a challenge to science. Issues in Science and Technology 2: 20-29.

11. Wilson EO (2003) What is Nature Worth For? Part 1: Span ZLIV-4: 54-57 Part 2: XLIV, 23-29.

12. Wilson EO (1992) The diversity of life. Harvard University Press, Belknap, Cambridge

13. Cardoso P, Arnedo MA, Triantis KA, Borges PAV (2010) Drivers of diversity in Macaronesian spiders and the role of species extinctions. Journal of Biogeography 37: 1034-1046.

14. Régnier C, Fontaine B, Bouchet $P$ (2009) Not knowing, not recording, not listing: numerous unnoticed mollusk extinctions. Conservation Biology 23: 1214-1221.

15. Triantis KA, Borges PAV, Ladle RJ, Hortal J, Gaspar C et al. (2010) Extinction debt in oceanic islands. Ecography 33: 285-294.

16. Narendran TC (2006) An Introduction to Taxonomy. Zoological Survey of India publication. (Ed. Director Zoological Survey of India) Kokatta 1-80 $\mathrm{p}$.

17. Narendran TC (2008) Importance of Taxonomy in Conservation of Biodiversity 14-19 pp. Wild Life Biodiversity Conservation (Ed. Reddy M.V.). Daya Publishing House, Delhi 1-390

18. Lincoln R, Boxshall G, Clark PA (1998) A dictionary of Ecology, Evolution and Systematics. Cambridge University Press. Cambridge.

19. Wägele JW (2005) Foundations of Phylogenetic Systematics. Verlag Dr. Friedrich Pfeil. München, Germany.

20. Godfray HC (2002) Challenges for taxonomy. Nature 417: 17-19.

21. Godfray HC (2002) Towards taxonomy's 'glorious revolution'. Nature 420: 461.

22. Tautz D, Arctander P, Minelli A, Thomas RH, Vogler AP (2003) A plea for DNA taxonomy. Trends in Ecology and Evolution 18: 70-74.

23. Linnaeus C (1758) Systema naturae per regna tria naturae, secundum classes, ordines, genera, species, cum characteribus, differentiis, synonymis, locis Editio decima. Holmiæ (= Stockholm): Laurentius Salvius.

24. Kapoor VC (1998) Principles and practices of animal taxonomy. Science Publishers.

25. Disney H (2000) Hands-on taxonomy. Nature 405: 307.

26. Huxley JS (1940) The new systematic. The Clarendon Press, Science 583 pages

27. Grimaldi DA, Engel MS (2007) Why descriptive science still matters. View Point. BioScience 57: 645-646.

28. Narendran TC (2000) The Importance of Systematics. Resonance 5 60-68.

29. Narendran TC (2003) Role of Taxonomy in Biological Control and in Insect Pest Management in India. Biol. Control Insect Pests. (Eds. Ignacimuthu \& Jayaraj S.) 250-255.

30. Schauff ME, La Salle J (1998) The relevance of systematics to biocontrol protecting the investment in research; Pest Management-Future Challenges. (Eds. Zalucki M.P., Drew R.W.I. and White G.G., Proceedings of the Sixth Austrasian Applied Entomological Research Conference, Brisbane. 425-436.

31. Narendran TC (2001) Taxonomic Entomology: Research and Education in India. Current Science 8: 445-447.
32. Ebach MC, Valdecasas AG, Wheeler QD (2011) Impediments to taxonomy and users of taxonomy: accessibility and impact evaluation. Cladistics 27: 1-8.

33. McCook LJ, Ayling T, Cappo M, Choate JH, Evans RD (2010) Adaptive management of the Great Barrier Reef: A globally significant demonstration of the benefits of networks of marine reserves. Proceedings of National Academy of Sciences 107: 18278-18285.

34. Mora C, Tittensor DP, Adl S, Simpson AGB (2011) How many species are there on Earth and in the Ocean. PLoS Biology 9: e1001127.

35. Wheeler QD, Raven P, Wilson EO (2004) Taxonomy: impediment or expedient? Science 303: 285.

36. Evenhuis NL (2007) Helping solve the "other" taxonomic impediment: completing the eight steps to total enlightenment and taxonomic nirvana. Zootaxa 1407: 3-12.

37. Gewin V (2002) All living things, online. Nature 418: 362-363.

38. Simonetti JA (1997) Biodiversity and a taxonomy of Chilean taxonomists. Biodiversity and Conservation 6: 633-637.

39. Wägele H, Klussmann-Kolb A, Kuhlmann M, Haszprunar G, Lindberg D ET AL. (2011) The taxonomist - an endangered race. A practical proposal for its survival. Frontiers of Zoology 8: 25.

40. Van der Velde G (2001) Taxonomists make a name for themselves. Nature 414: 148.

41. Werner YL (2006) The case of impact factor versus taxonomy: a proposal. Journal of Natural History 40: 1285-1286.

42. Werner YL (2009) The aspiration to be good is bad: The "Impact Factor" hurts both science and society. International Journal of Science in Society 1: 99-105.

43. Cotterill FPD (1995) Systematics, biological knowledge and environmental conservation. Biodiversity Conservation 4: 183-205.

44. Gaston KJ, May RM (1992) Taxonomy of taxonomists. Nature 356: 281-282.

45. Boero F (2001) Light after dark: the partnership for enhancing expertise in taxonomy. Trends Ecol Evol 16: 266-267.

46. Wheeler QD (2007) Invertebrate systematics or spineless taxonomy? In: Zhang, Z.Q. and Shear, W.A. (Eds.), Linnaeus tercentenary: Progress in invertebrate taxonomy. Zootaxa 1668: 11-18.

47. Wortley AH, Bennett JR, Scotland RW (2002) Taxonomy and phylogeny reconstruction: two distinct research agendas in systematics. Edinburgh Journal of Botany 59: 335-349.

48. Brooke ML (2000) Why museums matter. Trends in Ecology and Evolution 15: 136-137.

49. Garfield E (1955) Citation indexes to science: a new dimension in documentation through association of ideas. Science 122: 108-111.

50. Cross J (2009) Impact factors- the basics. In: The e-resources management handbook (ed. Graham, S.,) 10.1629/9552448-0-3.17.1, Chapter 18, 1-12

51. Garfield E (1994) The impact factor. Current Contents 25: 3-7.

52. Shubbert E (2012) Use and misuse of the Impact Factor. Systematics and Biodiversity 10: 391-394.

53. Boero F (2010) The Study of Species in the Era of Biodiversity: A Tale of Stupidity. Diversity 2: 115-126.

54. Seglen PO (1997) Why the impact factor of journals should not be used for evaluating research? British Medical Journal 314: 497-508.

55. Krell FT (2002) Why impact factors don't work for taxonomy. Nature 415: 957.

56. Valdecasas, AG, Castroviejo S, Marcus LF (2000) Reliance on the citation index undermines the study of biodiversity. Nature 403: 698.

57. Lawrence PA (2007) The mis measurement of science. Current Biology 17: 583-585.

58. Mani MS (1989) From the Editor. Hexapoda 1: I.Marder E., Kettenmann H. \& Grillner S. 2010, Impacting our young. Proceedings of National Academy of Sciences 107: 21233

59. Krell FT (2000) Impact factors aren't relevant to taxonomy. Nature 405 : $507-508$ 
60. Chakrabarty P (2010) Genetypes: A Concept to Help Integrate Molecular Phylogenetics and Taxonomy. Zootaxa 2632: 67-68.

61. Isaac NJB, Mallet J, Mace GM (2004) Taxonomic Inflation: Its Influence Macroecology and Conservation. Trends in Ecology \& Evolution 19: 464-469.

62. Queiroz K, Gauthier J (1992) Phylogenetic taxonomy. Annual Review of Ecology and Systematics 23: 449-480.

63. de Queiroz K, Gauthier J (1994) Toward a phylogenetic system of biological nomenclature. Trends of Research Ecology and Evolution 9: 27-31

64. Lee MSY (2001) On recent arguments for phylogenetic nomenclature. Taxon 50: 175-180.

65. Bryant HN, Cantino PD (2002) A review of criticisms of phylogenetic nomenclature: Is taxonomic freedom the fundamental issue? Biological Reviews 77: 39-55.

66. Cantino PD (2004) Classifying species versus naming clades. Taxon 53: 795-798.

67. Cantino PD, de Queiroz K (2004) PhyloCode: A Phylogenetic code of biological nomenclature.

68. de Queiroz K (2006) The PhyloCode and the distinction between taxonomy and nomenclature. Systematic Biology 55: 160-162.

69. Härlin M (2005) Definitions and phylogenetic nomenclature. Proceedings of the California Academy of Sciences, 56: 216-224.

70. Sereno PC (2005) The Logical Basis of Phylogenetic Taxonomy. Systematic Biology 54: 595-619.

71. Laurin M, Cantino PD (2004) First international phylogenetic nomenclature meeting: a report. Zoologica Scripta 33: 475-479.

72. Lidén M, Oxelman B (1996) Do we need phylogenetic taxonomy? Zoologica Scripta 25: 183-185.

73. Dominguez E, Wheeler QD (1997) Taxonomic stability is ignorance. Cladistics 13: 367-372.

74. Nixon KC, Carpenter JM (2000) On the other "phylogenetic systematics", Cladistics 16: 298-318

75. Benton MJ (2007) The Phylocode: Beating a dead horse? Acta Palaeontologica Polonica 52: 651-655.

76. Dyke GJ (2002) Should palaeontologists use "phylogenetic" nomenclature? Journal of Paleontology 76: 793-796.

77. Forey PL (2002) PhyloCode: pain, no gain. Taxon 51: 43-54.

78. Carpenter JM (2003) Critique of Pure Folly. Botanical Reviews 69: 79-92.

79. Keller RA, Boyd RN, Wheeler QD (2003) The illogical basis of phylogenetic nomenclature. Botanical Reviews 69: 93-110.

80. Nixon KC, Carpenter JM, Stevenson DW (2003) The PhyloCode is fatally flawed, and the "Linnaean" system can easily be fixed. Botanical Reviews 69: 111-120.

81. Monsch KA (2006) The PhyloCode, or alternative nomenclature: why it is not beneficial to palaeontology, either. Acta Palaeontologica Polonica 51: 521-524.

82. Rieppel OC (2006) The PhyloCode: a critical discussion of its theoretical foundation. Cladistics 22: 186-197.

83. Benton MJ (2000) Stems, nodes, crownclades, and rank-free lists: is Linnaeus dead? Biol Rev 75: 633-648.

84. Krell FT (2004) Parataxonomy vs. Taxonomy in biodiversity studies pitfalls and applicability of 'morphospecies' sorting. Biodiversity Conservation 13: 795-812.

85. Shiyang K, Srivathsan A, Meier R (2012) An update on DNA barcoding: low species coverage and numerous unidentified sequences. Cladistics 28:639-644

86. Graham CH, Ferrier S, Huettman F, Moritz C, Peterson AT (2004) New developments in museum-based informatics and applications in biodiversity analysis. Trends in Ecology and Evolution 19: 497-503.

87. Dubois A (2003) The relationships between taxonomy and conservation biology in the century of extinctions. C R Biol 326: S9-S21.

88. Dubois A (2010) Describing new species. Taprobanica 2: 6-24.
89. Cordoso P, Erwin TL, Borges PAV, New TR (2011) The seven impediments in invertebrate conservation and how to overcome them. Biological Conservation 144: 2647-2655.

90. Nature (2002) Genomics and taxonomy for all. Nature 417: 573.

91. Golding JS, Timberlake J (2003) How taxonomists can bridge the gap between taxonomy and conservation science. Conservation Biology 17: 1177-1178.

92. Valdecasas AG, Camacho AI (2003) Conservation to the rescue of taxonomy. Biodiversity and Conservation 12: 1113-1117.

93. Fitzhugh K (2012) The limits of understanding in biological systematics. Zootaxa 3435: 40-67.

94. Gaston KJ, O'Neill MA (2004) Automated species identification: Why not? Philosophical Transactions of Royal Society London B 359: 655-667.

95. Eshera MA, Fu KS (1986) An image understanding system using attributed symbolic representation and inexact graph-matching. IEEE Trans. Pattern Analysis and Machine Intelligence 8: 604-618.

96. Cheng HD, Jiang XH, Sun Y, Wang J (2001) Color Image Segmentation: Advances and Prospects. Pattern recognition 34: 2259-2281.

97. Lowe DG (2004) Distinctive image features from scale-invariant keypoints. International Journal of Computer Vision 60: 91-110.

98. Klinker GJ, Shafer SA, Kanade T (1990) A physical approach to color image understanding. International Journal of Computer Vision 4: 7-38.

99. Rohlf FJ, Bookstein FL (2003) Computing the uniform component of shape variation. Systematic Biology 52: 66-69.

100. Reed TR, Hans du Buf JM (1993) A Review of Recent Texture Segmentation And Feature-Extraction Techniques. CVGIP: Image Understanding 57: 359-372.

101. De Carvalho MR, Bockmann FA, Amorim DS, de Vivo M, de ToldeoPiza (2005) Revisiting the taxonomic impediment. Science 307: 353.

102. De Carvalho MR, Bockmann FA, Amorim DS, Brandão CRF, de Vivo M (2007) Taxonomic impediment or impediment to taxonomy? A commentary on systematics and the cybertaxonomic-automation paradigm. BMC Evol Biol 34: 140-143.

103. De Carvalho MR, Bockmann MR, Amorim FADS, Brandão CRF (2008) Systematics must embrace comparative biology and evolution, not speed and automation. BMC Evolution and Biology 35: 150-157.

104. JCQAR: Joint Committee on Quantitative Assessment of Research (2008) Citation statistics. A report from the International Mathematical Union in cooperation with the International Council of Industrial and Applied Mathematics and the Institute of Mathematical Statistics $26 \mathrm{p}$.

105. MacLeod N (2007) Automated taxon identification in systematics: theory, approaches and applications. Systematics Association Special Volume 74: Boca Raton: Taylor \& Francis.

106. Hebert PDN, Cywinska A, Ball SL, de Waard JR (2003) Biological identifications through DNA barcodes. Philosophical Transactions of Royal Society London Series B-Biological Science 270: 313-321.

107. Hebert PDN, Gregory TR (2005) The promise of DNA barcoding for taxonomy. Systematic Biology 54: 852-859.

108. Will KW, Rubinoff D (2004) Myth of the molecule: DNA barcodes for species cannot replace morphology for identification and classification. Cladistics 20: 47-55.

109. Dayrat B (2005) Toward integrative taxonomy. Biological Journal of Linnaean Society 85: 407-415.

110. Ebach MC, Holdrege C (2005) DNA barcoding is not substitute for taxonomy. Nature 434: 697.

111. Katz R (2005) The problem with DNA barcoding: The whole is more than its parts. Flower Essence Society.

112. Ogura Y (1964) Comparative morphology and classification of plants. Phytomorphology 14: 240-247.

113. Boero F (2010) The study of species in the era of biodiversity: a tale of stupidity. Diversity 2: 115-126.

114. Rodman JE, Cody JH (2003) The taxonomic impediment overcome: NSF's Partnerships for Enhancing Expertise in Taxonomy (PEET) as a model. Systematic Biology 52: 428-435. 
Citation: Tahseen Q (2014) Taxonomy-The Crucial yet Misunderstood and Disregarded Tool for Studying Biodiversity. J Biodivers Endanger Species 2: 128. doi:10.4172/2332-2543.1000128

Page 9 of 9

115. Pyle RL, Earle JL, Greene BD (2008) Five new species of the damselfish genus Chromis (Perciformes: Labroidei: Pomacentridae) from deep coral reefs in the tropical western Pacific. Zootaxa 1671: 3-31.

116. Deans AR, Kawada R (2008) Alobevania, a new genus of neotropical ensign wasps (Hymenoptera: Evaniidae), with three new species Integrating taxonomy with the World Wide Web. Zootaxa 1787: 28-44.

117. Johnson NF, Masner L, Musetti L, van Noort S, Rajmohana K (2008) Revision of world species of the genus Heptascelio Kieffer (Hymenoptera: Platygastroidea, Platygastridae). Zootaxa 1776: 1-51.

118. Zhang ZQ (2008) Zoological taxonomy at 250: showcasing species descriptions in the cyber era. Zootaxa 1671: 1-2

119. Walters T, Scher J, Drake J (2008) Identification technology program in review. In CPHST Laboratory Fort Collins: Annual Report, 2007, 30-37 pp. USDA-APHIS-PPQ-CPHST, Fort Collins, Colorado.
120. Drake J (2009) Robotic Automated Pest ID. In CPHST 2008 Annual Report. USDA-APHIS-PPQ-CPHST, Raleigh, North Carolina.

121. Wilson EO (2004) Taxonomy as a fundamental discipline. Philosophical Transactions of Royal Society London B 359: 739.

122. May RM (2011) Why worry about how many species and their loss? PLoS Biol 9: e1001130.

123. Hennig, W (1966) Phylogenetic systematics. Urbana: Univ. of Illinois Press.

124. Nelson G, Platnick N (1981) Systematics and biogeography, cladistics and vicariance. New York: Columbia Univ. Press.

125. Rieppel OC (1988) Fundamentals of comparative biology. Basel: Birkhauser. 